\title{
(Richie Fajar) \\ الأعمال الطبية الحديثة بين الأحكام الفقهية والقانون الإندونيسي \\ (دراسة مقاصدية في طفل الأنابيب و منع الحمل و زراعة الاحمد الأعضاء)
}

\author{
Richie Fajar \\ Kartopuran, Jayengan, Serengan, Surakarta \\ E-Mail: khurun_ien@yahoo.co.id
}

\begin{abstract}
A The purpose of this study is to describe the surgery of modern medicine in in vitro fertilisation (IVF), contraception and organ transplants between Indonesian regulation, it's seen from the viewpoint of "maqosidsyareahIslamiyah," and I started with definition of the surgery of modern medical, legal jurisprudence, legislation and maqosidsyareah, then an explanation of the applicable regulations, and laws maqosid of the review that took place in Indonesian society.in this study I used qualitative research and literature, by reading medical books required and books of figh contemporary for completeness, then I used the method of comparison, between the opinions of medicine and jurisprudence, and method of conclusions by looking at events that hit with a solution from the point of view of maqosid to keep human emergency law, of keeping religion, life, property, intellect, and descent, with the words of scholars in the application maqosidsyareah. Conclusions of law IVF, including temporary because of sterility of husband and wife, and this is permitted, other than one of the two or lease womb is forbidden like adultery, although there is a need and treat infertile, thenvasectomy and tubal ligation including emergency contraception is forever, the rest, including the need is temporary, except spiral, modern gelding, and implants that could be forever, then autograft, isograft, and allograft included in the emergency laws if they can help the lives, while the rest, including the need if it's proven to be beneficial.
\end{abstract}

Keywords: medical surgery, Indonesian regulations, Figh maqosid

\begin{abstract}
Abstrak: Tujuan tesis ini menjelaskan operasi medis modern dalambayi tabung, kontrasepsi dan transplantasi organ antara undang undang Indonesia dan hokum fiqih, dilihat dari sudut pandang "maqosid syareah islamiyah", dan saya mulai dengan pengertian operasi medis modern, hukum fiqih, undang-undang dan maqosid syareah, kemudian penjelasan tentang ketentuan yang berlaku, serta hokum maqosid dari tinjauan yang terjadi di masyarakat Indonesia.Saya berpedoman dalam penelitian ini dengan studi kualitatif dan kepustakaan, dengan membaca buku kedokteran yang diperlukan dan buku fiqih kontemporer untuk kelengkapanya, kemudian saya gunakan metode perbandingan, antarapendapat kedokteran dan fiqih, dan metode kesimpulan dengan melihat kejadian yang melanda dengan solusi dari sudut pandang maqosid untuk menjaga hukum darurat manusia, dari menjaga agama, jiwa, harta, akal, dan keturunan, dengan perkataan ulama dalam penerapan maqosid syareah. Kesimpulan dari hukum bayi tabung, termasuk kebutuhan dengan sebab mandulnya suami istri, dan ini dibolehkan, selain salah satu dari keduanya atau sewa rahim haram mirip zina,walau ada kebutuhan dan mengobati mandul, kemudian vasektomi dan tubektomi termasuk kontrasepsi darurat bersifat selamanya, sisanya termasuk kebutuhan bersifat sementara, kecuali spiral, kebiri modern, dan implant yang bisa bersifat selamanya, kemudian autograft, isograft, dan allograft termasuk dalam hukum darurat jika mampu menolong nyawa, adapun sisanya termasuk kebutuhan jika terbukti bermanfaat.
\end{abstract}

Kata kunci: operasi medis, UU Indonesia, fiqih maqasid 
الحلاصة: إستهدف هذا البحث بيان الأعمال الطبية

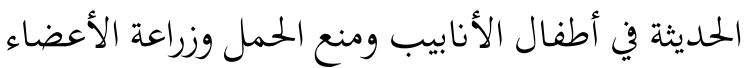

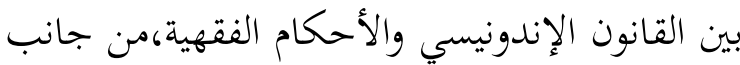

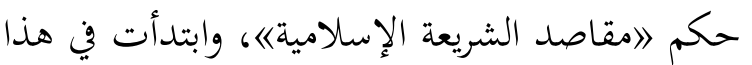

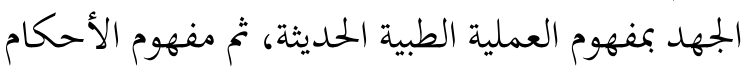

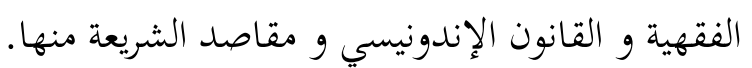

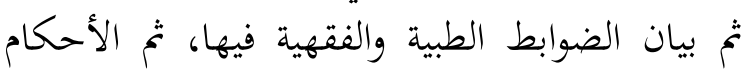

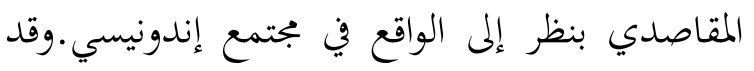

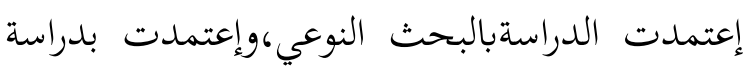

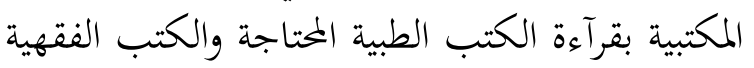

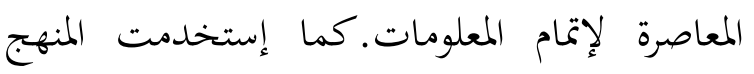
المقارن,وذلك بمقارنة بين موقف الطب و الفقه.والمنهج

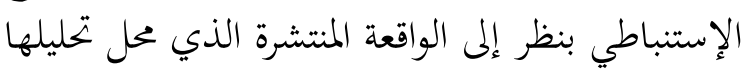

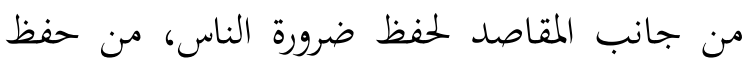

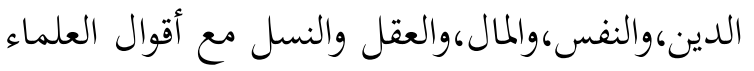

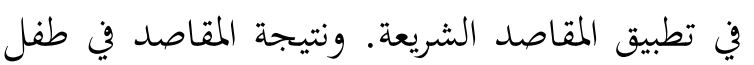

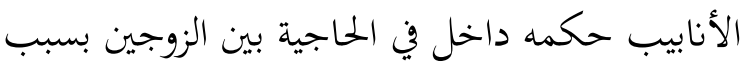

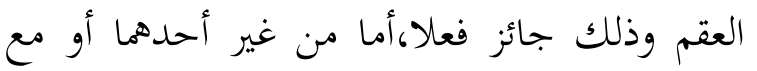

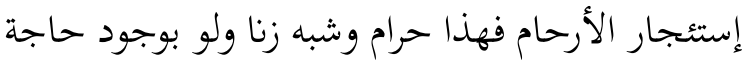

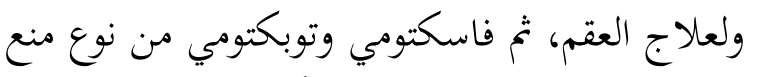

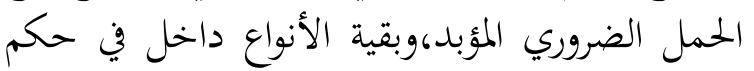

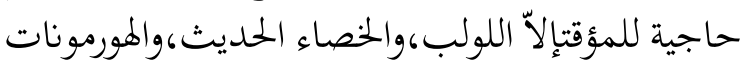
الجلدية الإمتصاص في نوع حاجية دائمة دالثم غريسة

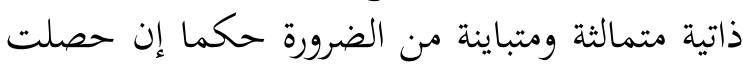
إنقاذ الحياة وبقية الأنواع في الغريسة حكمه كالفية كالحاجية

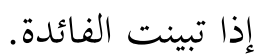

كلمات مفتاحية: الأعمال الطبية، القانون الإندونيسي، فقه المقاصد.



تطورات العلمية لما دور في حياة الإنسان خاصة في مجال الصحة الطبية.ولكن بالأسف بعض دور الإنس المسلمين

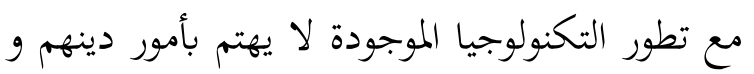
شريعتهم تم يتساهل في إستعمال المقاصد يحلّون ما حرّم لمرّم
الله و يحمّمون ما أحلّ الله ولا حول ولا قوة إلاّ بالله، وين ناحية أخرى منهم من يجمع بين الأصالة و المعاصرة

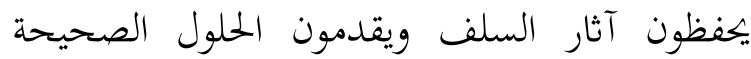

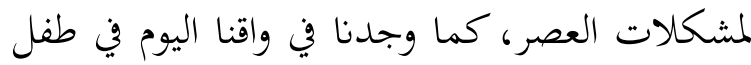

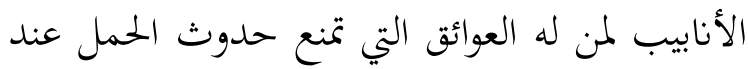

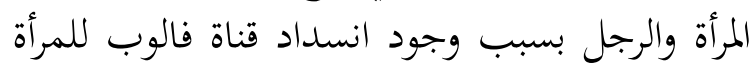

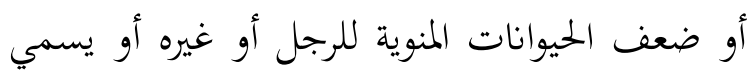

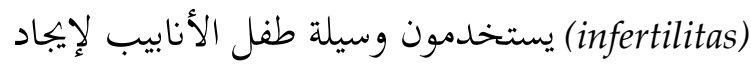

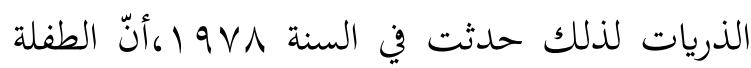

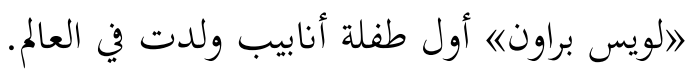

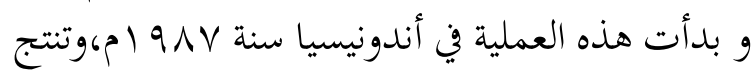

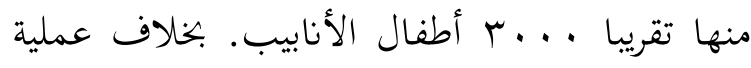

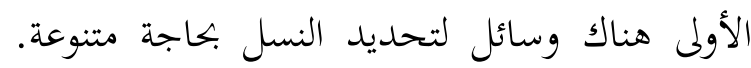

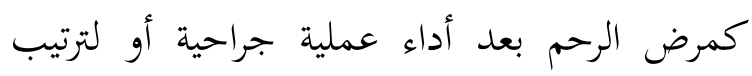

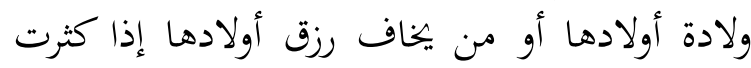

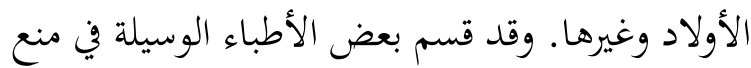

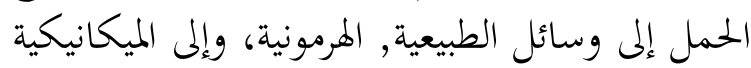

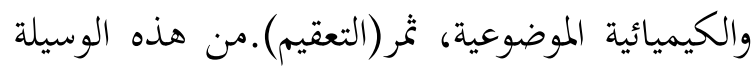

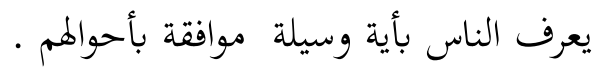
وبعضهم من يحتاج لعلاج مرض جسمه أو فقدان أعضان بعض أعضاء جسمه حتى يظهر عملية زرع الأعضاء

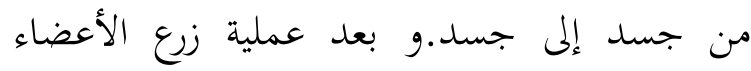
الناجح في السنة ع0 190 م م ، كثر طلبها لدئ لدي المجتمع.

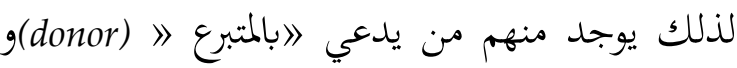

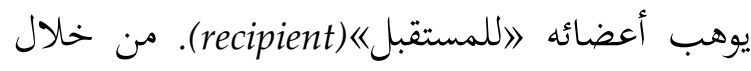
خلفية البحث السابقة يمكن عرض مشكلة البحث من منائه

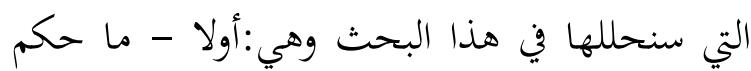

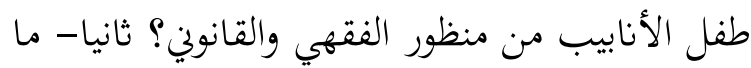

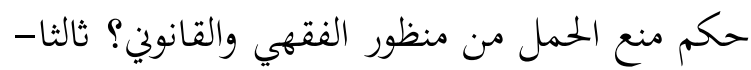

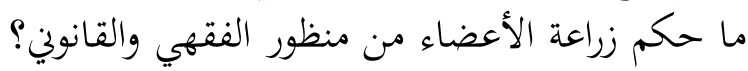

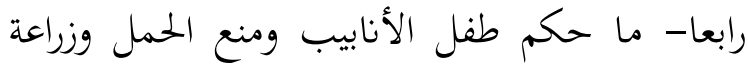

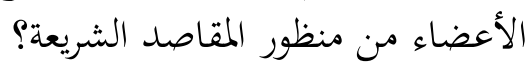

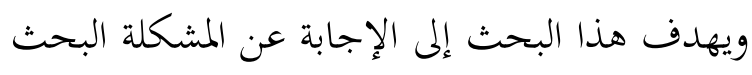

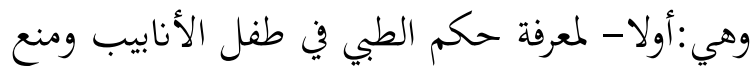

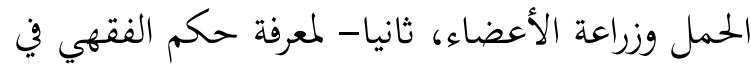

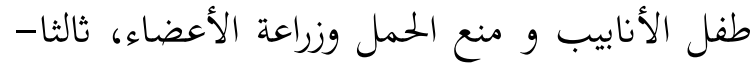


لمعرفة حكم المقاصد في طفل الأنابيب و منع الحمل وزراعة الأعضاء. والدراسات السابقة في هذا البحث كالمقارن مع هذا الباء

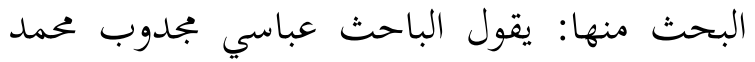

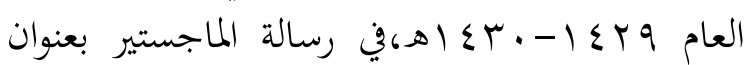

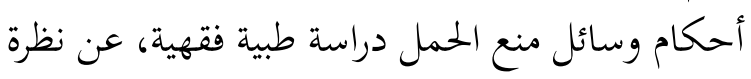

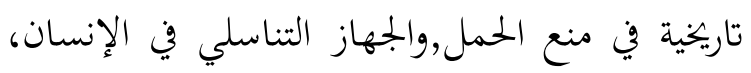

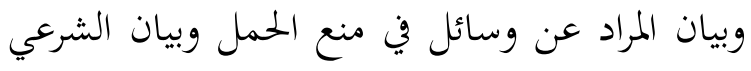

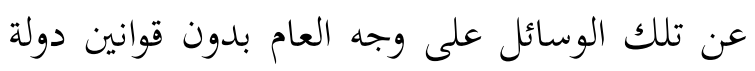

معينة. وفي رأي زياد أحمد سلامة في كتابه أطفال الأنابيب

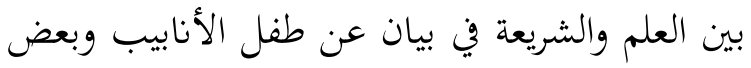
الأسباب الداعية إلى عملية طفل الأنابيب ولئ والأثار

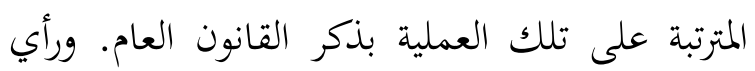

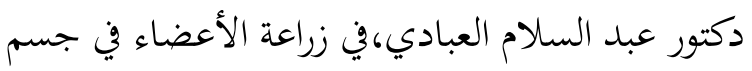

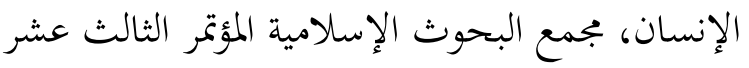

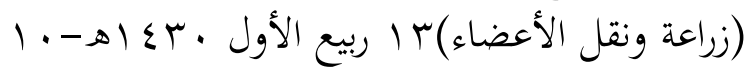

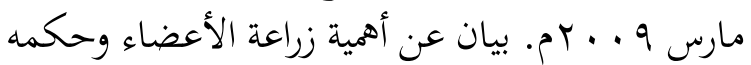

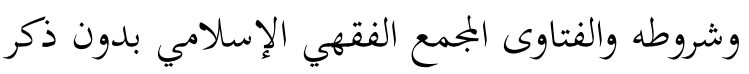
حكم القانون.

\section{منهجية البحث:}

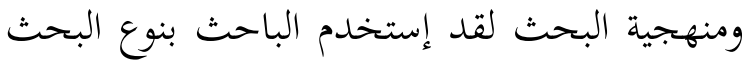

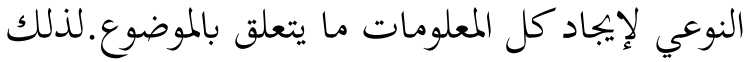

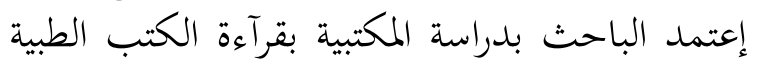

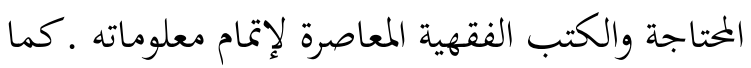

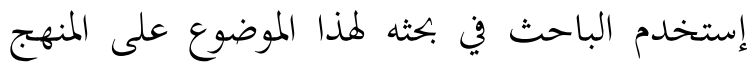

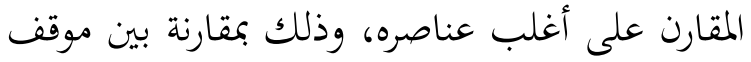

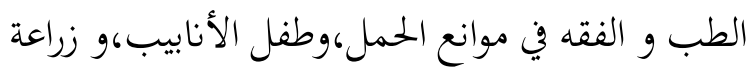
الأعضاء، بقصد تحديد أوجه الوفاق والإختلاف بلمن بينهما

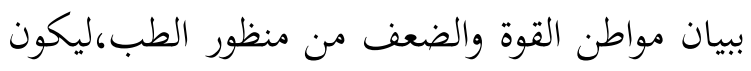

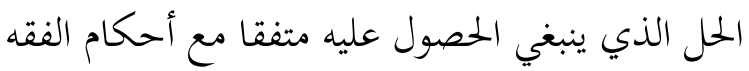

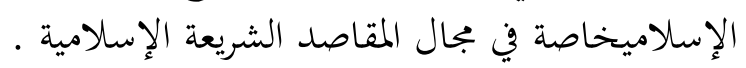

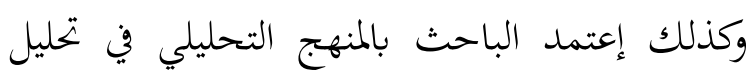
الأحكام الطبية و الأحكام الفقهية وحكم إستخدام

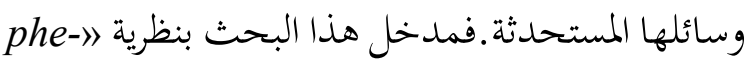
\&nomenologis
الظاهرة في المجتمع وكشفها والتعارف على حال من أحوالها، ويستنبط منها كالحلول والإجابة لتلك وكئك الظاهرة

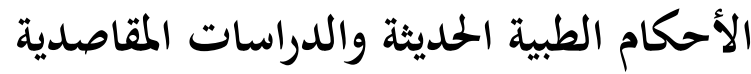
فيها الطب هو:فن من فنون العلاج الذي إجتمع فيه

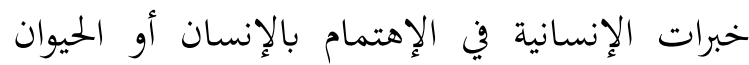
من مرض وإصابة الشيء في بلدنه أو نفسيته.والطب الإنب الطبان

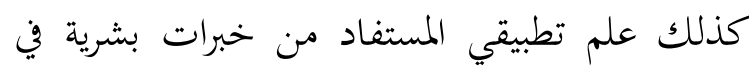

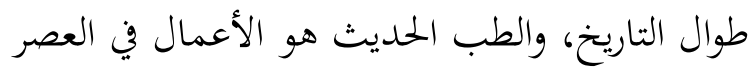
الحديث الذي يعتمد على الدراسات العملية الموثقة. ومن هذه القضايا الطبية :

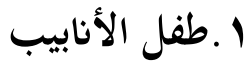



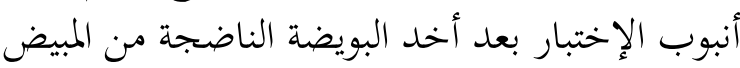

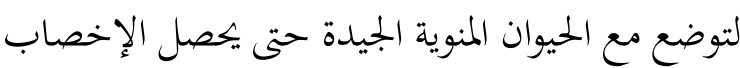

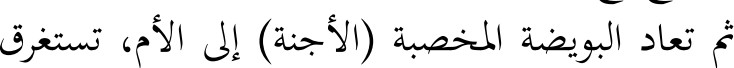

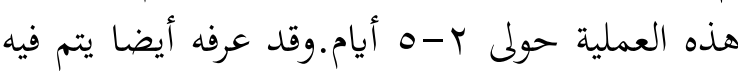

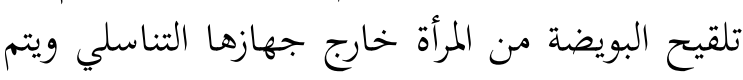

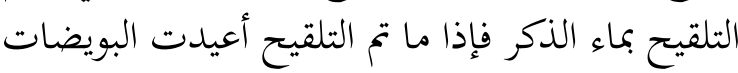

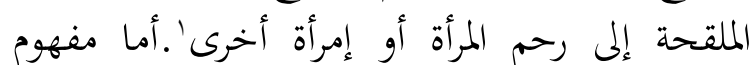
مقاصد الشريعة في طفل الأنابيب يعني الأحكام التي

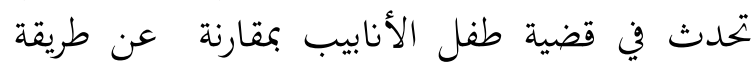
معرفة المقاصد ومراعات مصالح العباد فيها من الأمور

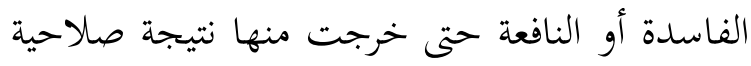

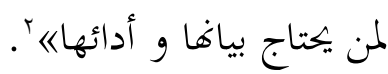

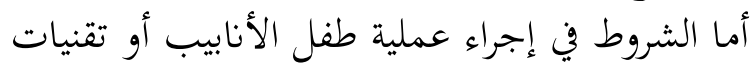

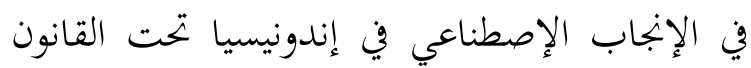

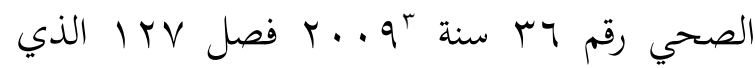

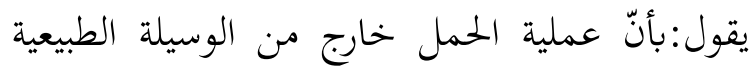

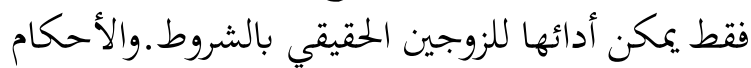

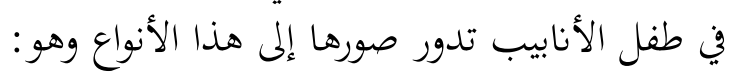

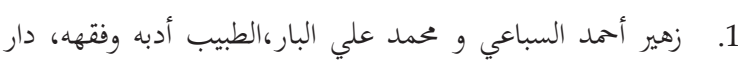

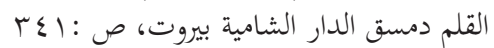

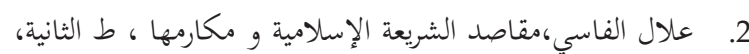
r

3. Peraturanmenterikesehatan republic Indonesia no 039/Menkes/SK/1/2010 hal:1 
الأول: الطفل الأنابيب بماء الزجين وهنا ثلاثة صور

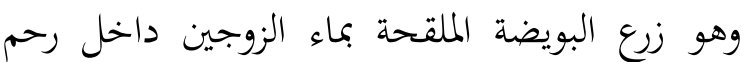

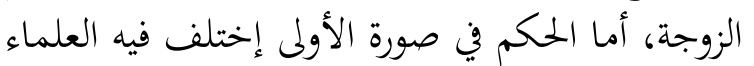

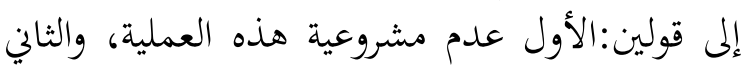

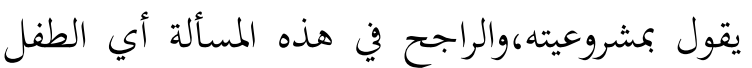

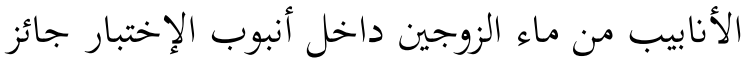

$$
\text { بالضوابط }
$$

الثانية :زرع البويضة الملقحة بماء الزوجين داخل

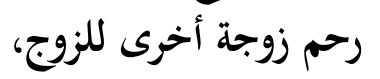

والحكم فيه خلاف والراج الراجح في هذه المسألة القول

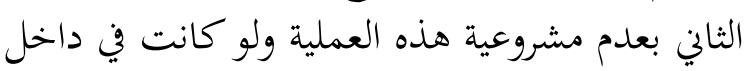

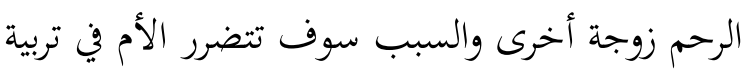

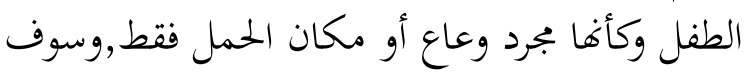

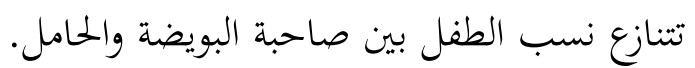
الثالثة: زرع البويضة الملقحة بماء الزوجين البطين في رحم

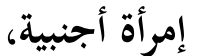

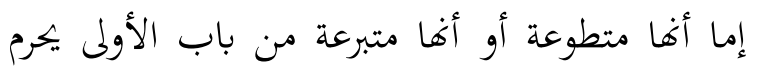



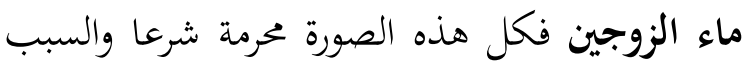

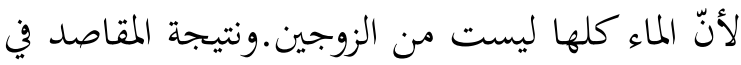

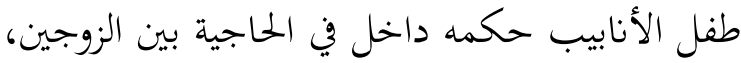

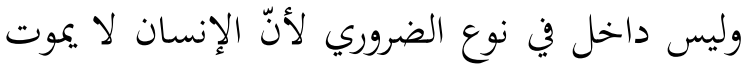

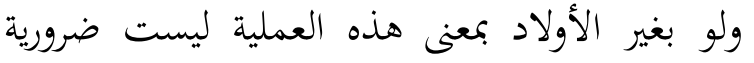

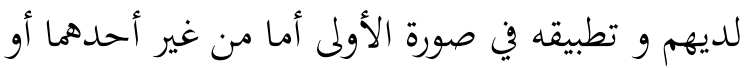

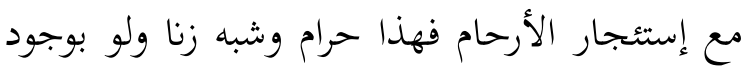

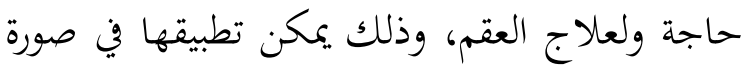
الثانية والثالثة.

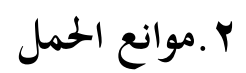
وهو نوعان:مؤقت ومؤبد، تعريف مؤقت :التوقف من

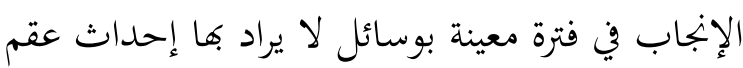

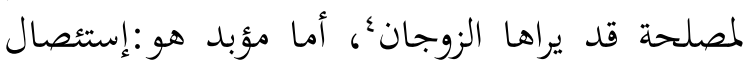

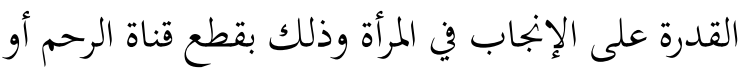

4. منصور،الأحكام الطبية المتعلقة بالنساء في الفقه الإسلامي،دار

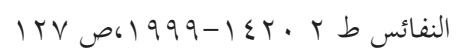

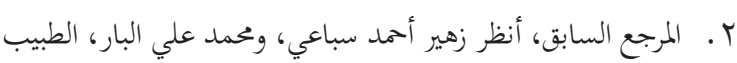

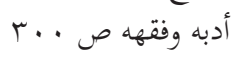

ربطها أو الإثنين معا، مفهوم مقاصد الشريعة في منع إنح

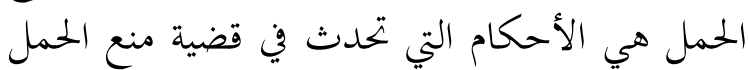

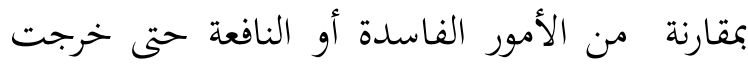

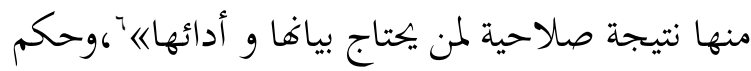

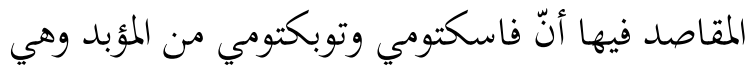

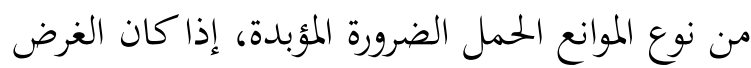

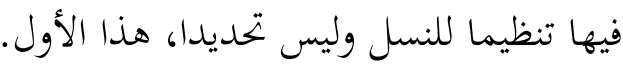

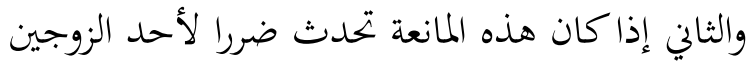

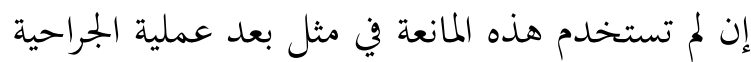

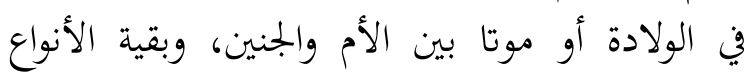

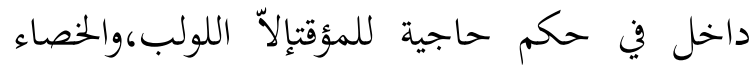

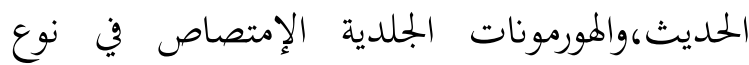
حاجية دائمة أو وسيلة إليها إذا أستخدمت لمبلدية لسنين طويلة، بغرض تنظيما لنسل وليس تحديدا.

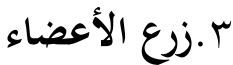

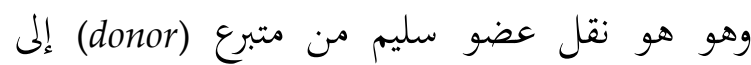

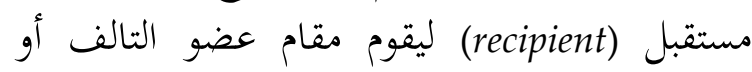

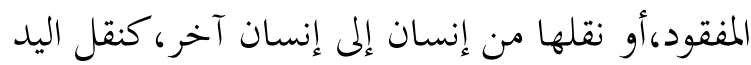

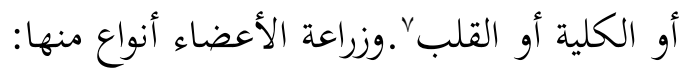

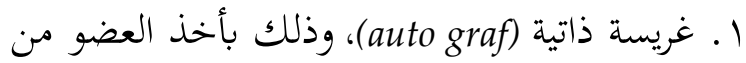
دائرة إلى دائرة أخرى في نفس الجسبم، و و من المثال قد

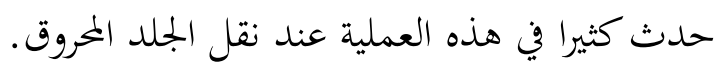

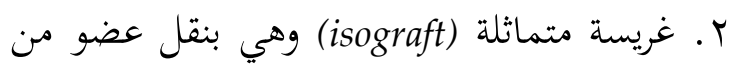

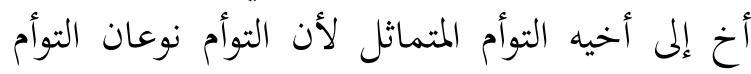



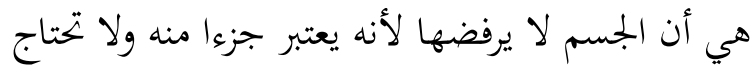
إلى إستخدام عقاقير خفض المبان المناعة.

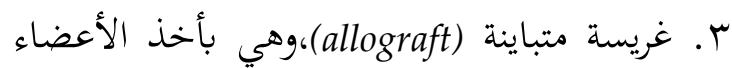

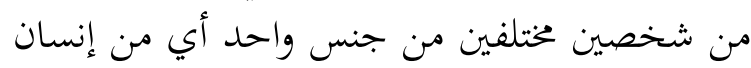

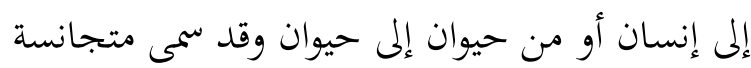
.(homograft) 5. ".المرجع السابق,أنظر علال الفاسي مقاصد الشريعة الإسلامية

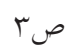

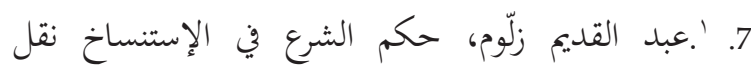

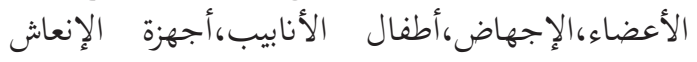

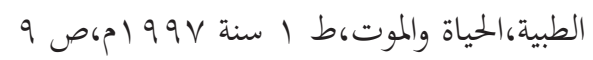




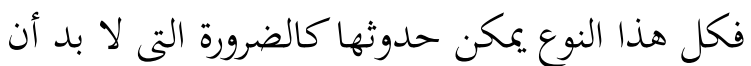

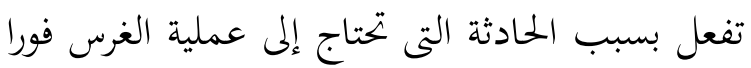

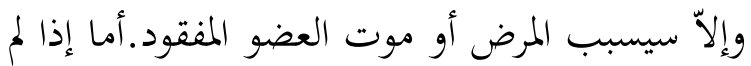

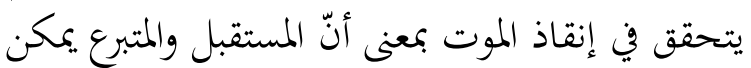

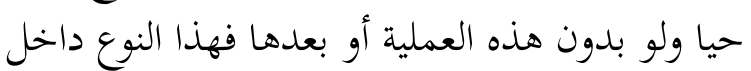
في حكم الحاجية عند المقاصد في مثل زراعة الكلوي.

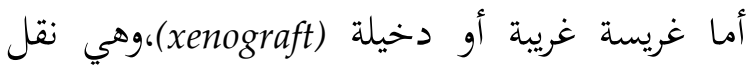

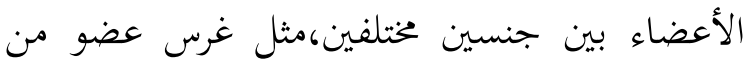
كلب إلى قط، (transplantasi split)وهي زئنسين الأعضاء بالتقسيم. (transplantasi domino) فهي زئي زراعة الأعضاء بعمليات الشراكة القلبية،.فكل هذا النوع داخل في حكم المقاصد الحاجية .

الحملاصة:

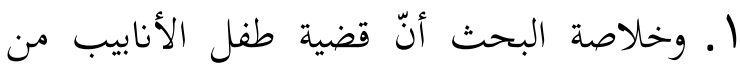

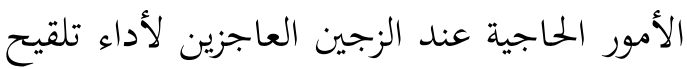

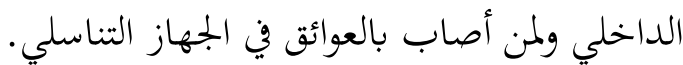

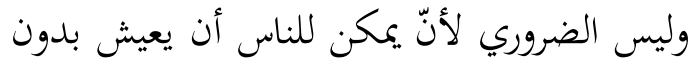
الأولاد أو الذريات.

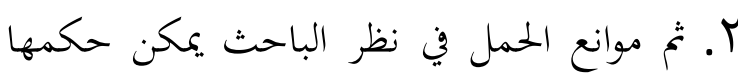
من جهة المقاصد الشريعة إلى الضرورة، والحاجية الماتية

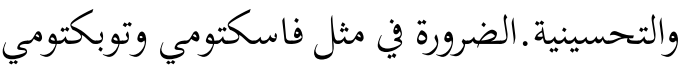
لأنّ إن لم يفعل سيلحق ضررا وهو الموت، إماكي موت الأم أو الولد، أو ضررا في رحم المرأة أو إل إن المان جسمها، والحاجية إذا كانت حاجة الزورجية الزين إليها

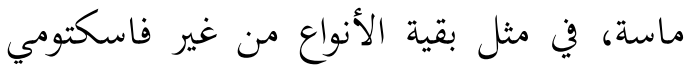

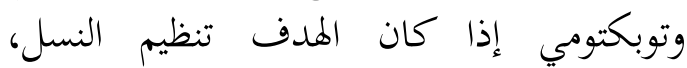

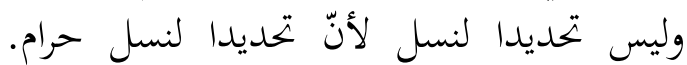
ويمكن وقوعها في التحسينية في غرض إستعال التمالها

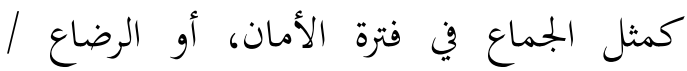
MAL Metode Amenore Laktasi النسل كل هذه نظرا بالواقع الموجود في إندونيسيا،

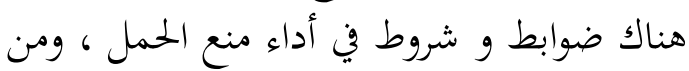

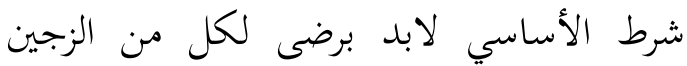

8. Lihat penjelasanya di https://ar.wikipedia.org/ زراعة الأعضاء/wiki
وبالغرض تنظيم النسل وليست تحديدا لنسلهم أو أو

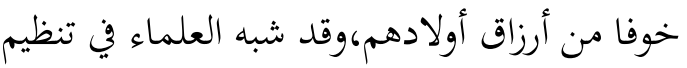

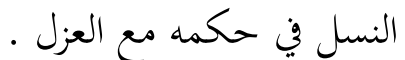
r. وغالبا عملية زرع الأعضاء من الأمور الضرورة إذا إنا

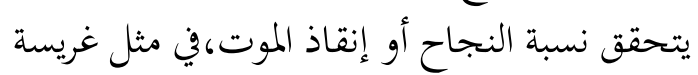
ذاتية، ومتماثلة، ومتباينة في أسباب الحادثة وإلاّاّ

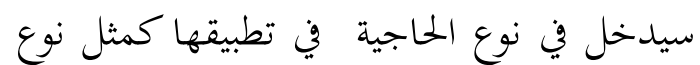

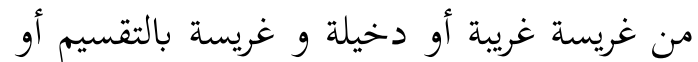
في غريسة الشراكة القلبية أو غيرها من الغريسة النافعة للإنسان. - النان

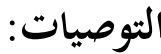

I. وأخيرا وصيتي كل من القضايا الطبية في طفل

الأنابيب وموانع الحمل وزراعة الأعضاء في أعمالها

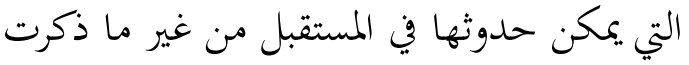
في هذا البحث لابد فعلها لأجل المقاص المقاصد المترتبة عند الناس لحفظ دينهم ونفسهم ومالهم وعقلهم ونسبهم أجمعين. Y. أن يهتم علماء المسلمين و أطبائهم في قضية

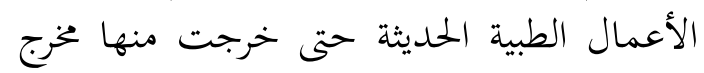

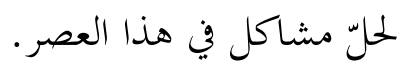
r. إستخدام موانع الحمل لعامة المسلمين في إندونيسيا

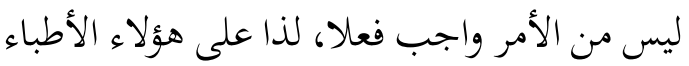

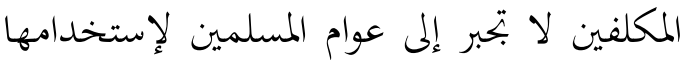
أو تخويفهم في غير إستعمالها سيحدث المبن أضرار الجسمية المعينة ع. لابد مع تطبيق العقوبات في القانون الإندونيسي المعائي لمن قد بحاوز حدا من الضوابط في إنجراء العملية حتى لا يحدث ضررا للناس خاصة أمة المسلمين، إنداء العملية إما من جانب العامل أو المفعول أي الطبيب

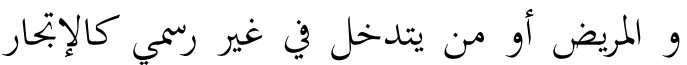
بالأعضاء البشري وغير ذلك من الجرائم.

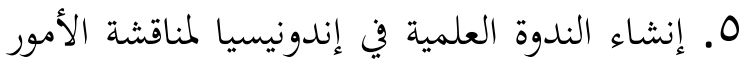

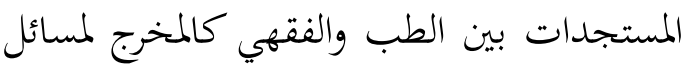
الأمة في إندونيسيا. 7. القانون الطبي لابد بمراعات مع الأمر الشرعي 


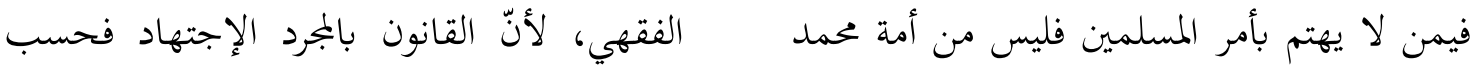

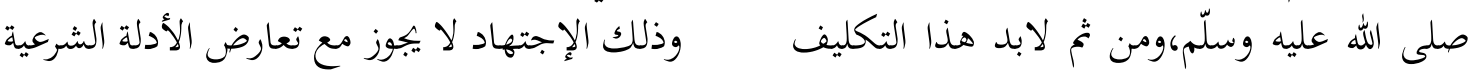

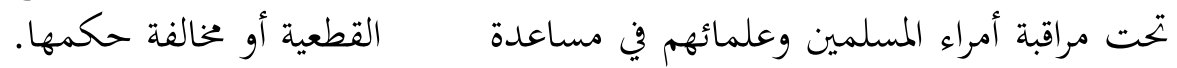

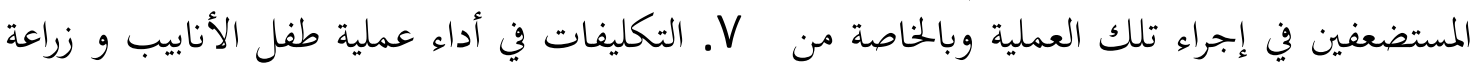

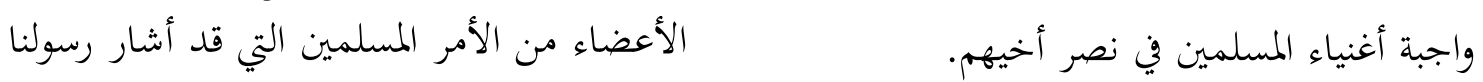

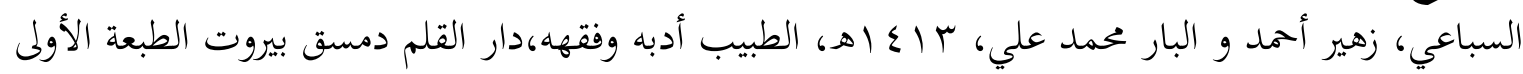

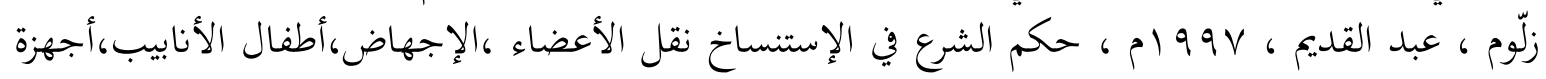

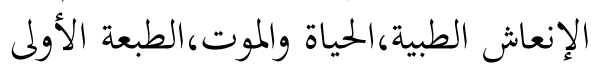

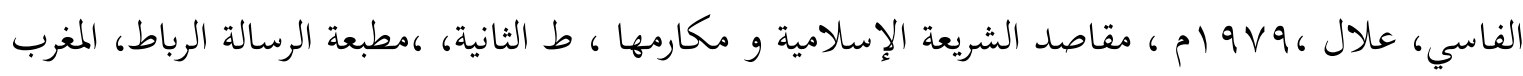

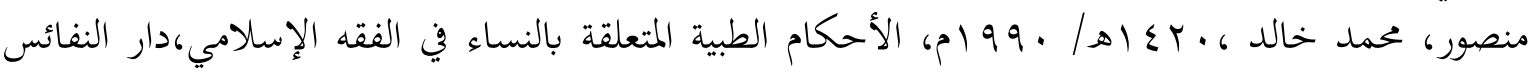
الطبعة الثانية

https://ar.wikipedia.org/wiki/زراعة الأعضاء peraturanmenterikesehatan republic Indonesia no 039/Menkes/SK/1/2010 